LA-UR $93-1928$

TITLE: CRYOGENIC COOLING SYSTEM FOR THE GROUND TEST ACCELERATOR

AUTHOR(S): Frederick J. Edeskuty, MEE-13

Walter F. Stewar, MEE-13

John Mo.ller, Grumman

Frank Durham, AT-DO

Ivers Spulgis, CVI Inc.

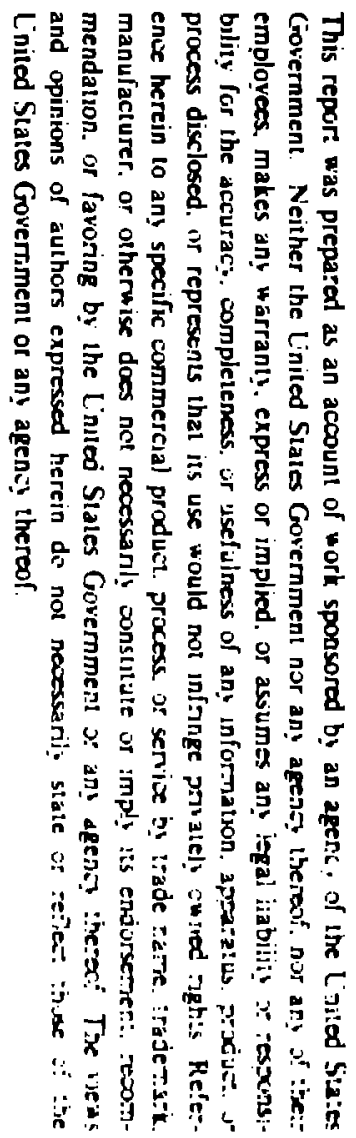

SUвMITREDTO: Cryogenic Engineering Conference July 12-16, 1993

Albuquerque, NM

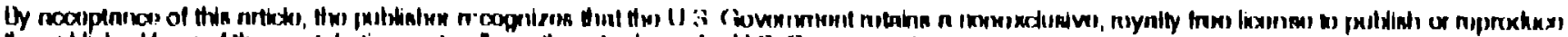

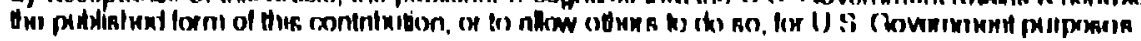

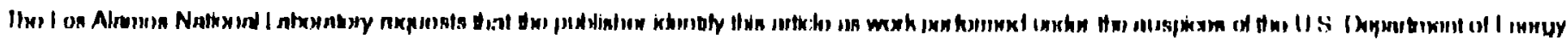

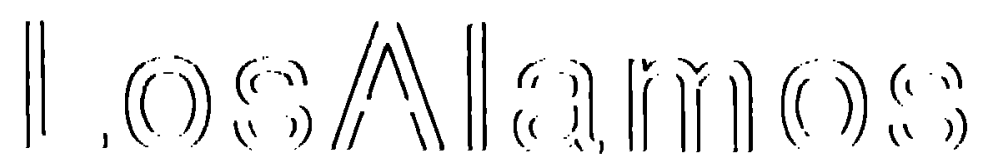

Los Alamos National Laboratory Los Alamos, New Mexico 87545 


\title{
CRYOGENIC COOLING SYSTEM FOR THE GROUND TEST ACCELERATOR
}

\author{
F. J. Edeskuty, W. F. Stewart, J. Moeller, F. Durham (Los Alamos National Laboratory), \\ and I. Spulgis (CVI, Inc.)
}

\section{ABSTRACT}

A cryogenic cooling system has been designed, built and tested for the Ground Test Accelerator (GTA) at the Los Alamos National Laboratory. Major components of the GTA require cooling to less than $50 \mathrm{~K}$ io reduce $\mathrm{f}$-heating and to increase thermal stability. The cooling system is capable of cooling (at an acceptable rate for thermal stresses) the cryogenically cooled components and then maintaining them at their operating temperature during accelerator testing for all modes and power levels of operation. The accelerator components are cooled by circulating cold, dense helium gas (about $21 \mathrm{~K}$ and $2.1 \mathrm{MPa}$ ) through the components. The circulating helium is refrigerated in a heat exchanger that uses boiling liquid hydrogen as a source of refrigeration. The cryogenic cooling system consists of the following major components: a liquid hydrogen $\left(\mathrm{LH}_{2}\right)$ storage Dewar with a transier line to an $\mathrm{LH}_{2}$ run tank containing arı $\mathrm{LH}_{2} /$ gaseous helium $(\mathrm{GHe})$ heat exchanger, circulation lines, and a circulation pump. The system, sized to $\mathrm{cool}$ a load of approximately $40 \mathrm{~kW}$ at temperatures as low as $20 \mathrm{~K}$, is operational, but has not yet been operated in conjunction with the accelerator.

\section{INTRODUCTION}

The GTA at the Los Alamos National Laboratory is an integrated-system test facility for evaluation of the use of neutral particle beams as a part of the Strategic Defens Initiative. The project is managed by the U.S. Army Strategic Defense Command for ii is Strategic Defense Iritiative Office.

The conceptual design and detailed specifications for the Cryogenic Cooling System (CCS) were developed by the Laboratory. As a result of competitive bidcing. a contract for design, procurement, fabrication, installation and acceptance lesting of the CCS was awarded to CVI, Inc.

The operation of the GTA at cryogenic temperature has two advantages 1,2 . First, the lower temperature produces, a corresponding decrease in the $\mathrm{ft}$-heating of thie copper in the various components of the acxelerator, and second, the decrease in the thermal expansion coefficient witi decreasing temperature provides greater theimal stability and consuquently, better operating stability for the accelerator. Although the ratio of the electri cal resistance of copper at room tempera ure to that at cryogenic temperature (RRR) can attain values well above 10!), this comparison does not hold for th heating. A typical theo retical ratio for if heating power for copper is sinown in Fir. 1 , which shows that most of the advantage of cryogenic cooling is chtalined when the temperature is lowered to $50 \mathrm{~K}$. A similar examination of the decrease: of the thermal expansion coellicient shows that most of the advantage in thermal stability is also obtained when the tomperature is lowered to the vicinity of $50 \mathrm{~K}$, where the reduction is sufficiont to permit satisiactory operation of the

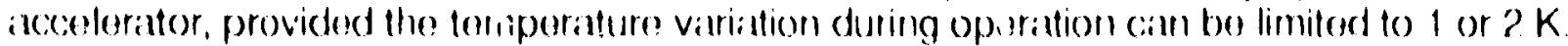

Thus, (ils operation requiros that the cryogenic: cooling system (1) cool part, or

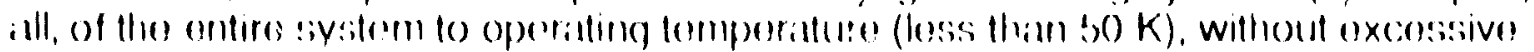

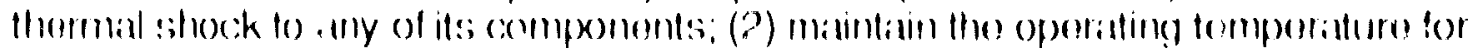


extended periods; and, (3) warm the components to ambient temperature at a controlled rate. The only fluids that can accommodate the requirement of operation below $50 \mathrm{~K}$ are neon, hydrogen, and helium.

The least expensive method of providing the refrigeration required for the intermittent cnoling during the test program is the use of liquid hydrogen that can be delivered to, and stored at, the test site. The normal boiling temperature of $\mathrm{LH}_{2}(20 \mathrm{~K})$ is close to the lowest temperature that is conveniently available for space applicaticns. This temperature is also sufficiently low to permit operation of the accelerator below $50 \mathrm{~K}$ while allowing for the temperature rise of the coolant that is necessary for single phase cooling, and allowing for the unavoidable temperature gradients within the accelerator components. However, because of safety restrictions, it is desirable to avoid the introduction of the hydrogen into the structure housing the acceleratur. For this reason the use of an intermediate coolant (a so-called referee fluid) was selected, with the only two possible fluids being neon or helium. The considerations involved in the selection of cold, dense helium gas instead of liquid neon have been discussed in detail elsewhere?

These considerations included the expense of the neon gas; for nenn, the necessity of operation at a nigher pressure to preclude any operation in thio two-phase regime; for helium, the greater ease of pressure control with changes in system cooling load; and the more complete knowledge of the properties of helium compared to tnuse of neon, especially with respect to properties related to heat transfer.

\section{SYSTEM DESCRIPTION}

A schematic of the selected conling system for the GTA is shown in Fig. 2. This system allows the GTA to be cooled at as slow a rate as necessary to avoid excess thermal gradients (consequently, also avoiding excess thermal stresses).

The cryogenic cooling system obtains its refrigeration capability from $\mathrm{L}_{2} \mathrm{H}_{2}$ purchased from a supplier and delivered to the GTA facility in a 50.000 liter (13.070 gallon) transport trailer. The liquid hydrogen is stored in a 106,000 liter (28,000 gallon) storage Dewar (see Fig. 3) and transferred through a $3.8 \mathrm{~cm}(1-1 / 2$ in.) vacusum-jacketed transfer line to the run Dewar (see Fig. 4). The hydrogen run Dewar coritains a helium tohydrogen heat exchanger to conduct the helium gas referee fluid through the pool-boiling hydrogen. Additional relrigeration is obtained by using the $20 \mathrm{~K}$ boil-off hydrogen vapor to cool the returning helium gas (at $35 \mathrm{~K}$ ) in an auxiliany heat exchanger before the hydrogen is exhausted and burned in a flare stack.

Tho hoat exchanger is connected to vacuum jackoted cryogenic transfor lines, which Hadd to a circulation compressor and to the GitA The inolium circulation systom primaaty concists of $8.6 \mathrm{~cm}$ (3 in.) valoum jacketed "go" and "roturn" limes. The primary cooling system also contans a liquid nitrogen (I $N$ :) rur: Dowar (sto l ig. 4; with liquid nitrogen to helium heast exchanger to allow tho use of k.w cost I Ne for protiminary cool down and itandby operation of tho sys:tom at $/ / \mathrm{K}$. A $40 \mathrm{~kW}$ heator is usod for rapid, but

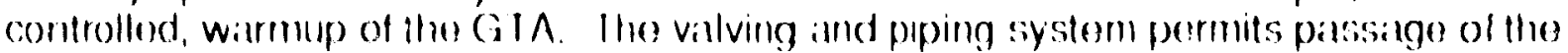

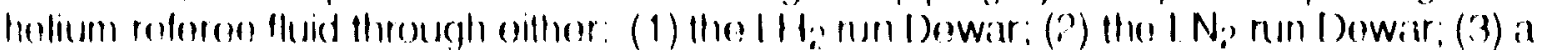

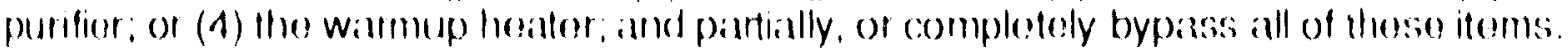

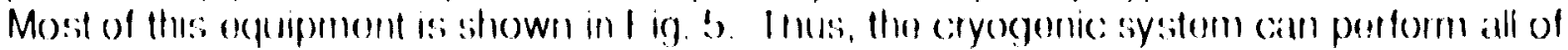

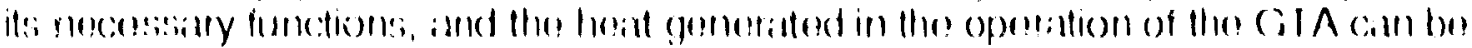

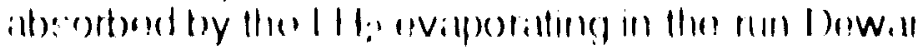


The accelerator heat load and pressure drop may be simulated by the warmup heater and control valve CV 151 (see Fig. 2).

Initially, the system, including the GHe-storage tank, is purged and then filled with pure G.He. Thereafter, the GTA and referee fluid system are charged with pure helium to the operating pressure of $2.1 \mathrm{MPa}$ from this inventory of $\mathrm{GHe}$. The helium gas is then circulated at ambient temperature through a juritier foi one hour to remove trace amounts of moisture and other impurities. During cool down of the system $\mathrm{GHe}$ is added as needed to maintain the pressure at 2.1 MPa.

Cool-down begins with circulating the reieree fluid through the heat exchanger in the L. $N_{2}$ run Dewar. A program in the Alien Bradley computer control system controls the bypass of a fraction of the flow from the $\mathrm{LN}_{2} / \mathrm{GHe}$ heat exchanger so as not to exceed a temperature differential of $50 \mathrm{~K}$ across the GTA. As the temperature of the GTA decreases, the bypass fraction is reduced by the controller until the bypass valve is fully closed and the bypass fraction becomes zero. When the temperature of the GTA approaches $80 \mathrm{~K}$ the flow of the referee fluid is redirected through the $\mathrm{LH}_{2}$ run Dewar and the cooling process continues to the operating temperature of $20 \mathrm{~K}$.

During a short standby period, cooling can be maintained with the referee fluid flowing through the $\mathrm{LH}_{2}$ cooled heat exchanger. For longer standby periods the flow can be redirected through the L.N2 Dewar when the GTA has warmed to $75 \mathrm{~K}$, and be maintained at that temperature as long as desired. Note that in all cases, the only fluid entering the GTA is the referee fluid. The system can remain on $\mathrm{LH}_{2}$ standby for $36 \mathrm{~h}$ for no more expenditure of $\mathrm{LH}_{2}$ than that requiled to cool the GTA fiom 77 to $20 \mathrm{~K}$.

During the accelerator's transition from zero power to ful! power the temperature of the fluid in the return portion of the helium circulation system increases from $21 \mathrm{~K}$ to $35 \mathrm{~K}$ in a period of about one miriute; consequently, some $\mathrm{GHe}$ is removed from the system with a two stage compressor to inaintain a relatively constant operating pressure. The same two-stage compressor adds helium to maintain system pressure during reductions in GTA operating power (and consequent lowering of temperature in the return portion of the helium circulation system).

The cooling system is operational and has been tested at it: maximum capacity of $40 \mathrm{~kW}$ at $20 \mathrm{~K}$. This checkout operation was performed independently from the GTA by the use of the accelerator load valve CV151 in the GiTA tunnel and the supply of heat from the $40 \mathrm{~kW}$ heater (see Fig. 2). CV151 also served to simulate the pressure drop through the GIA. A view of the CV151 and the piping in the tunnel is shown in Fig. 6

\section{TESTING AND CHECKOUT RESUITS}

The cryog rnic cooling system has been checked out and successfully operated at its dessign point of $40 \mathrm{~kW}$ with the uso of a dummy load. Figures 7 and 8 present the terinperalure and pressure histories of the checkout run. From fig. 7. it can be saen that the cryogenic cooling system can be cooled from ambient temperature to $77 \mathrm{~K}$ in loss than 180 minutes. Tine lurther cooling to ?0 K tatkes about 60 minutes. The rise in refurn holium fomperature to about $35 \mathrm{~K}$ during the application of $40 \mathrm{~kW}$ is evident in the time period from 400 to $4 / 0$ minutes. Ihe system was warmod back to ambient tomperature in approximatnly $1: 00$ minutes. Because this was only a test of the cooling system, it 
must be noted that the cool down and warm uip of the GTA will be slower, being dictated by the GTA mass to be cooled (or warmed) and the cooling rate and heating rate that it can tolerate.

Figure 8 shows the variation of pressure during the checkout run. The time period between 250 and 300 minutes shows drops in He pressure when the cool down is complete and when the cooling load is terminated. However, Fig. 8 shows that over the entire test period the pressure was maintained within a tolerable range.

\section{CONCLUSION}

The checkout run of the GTA cryogenic cooling system has shown that all systems are functioning satisfactorily. Cold, dense helium gas can be used as a referee fluid. Pressure control can be maintained through heat load changes, and the circulation compressor is capable of supplying the required $\mathrm{He}$ coolant flow at the required pressisre drop.

\section{REFERENCES}

1. T. E. Horton, "Oryogenic Requirements for n ion Beam Accelerators," Cryogenic Processes and Equipment-1993, F. J. Kadi, N. Chatterjee, and L. Wenzel, Eds., (the Arnerican Society of Mechanical Engineers, New York, 1993). pp 55-61.

2. F. J. Ecieskuty and W. F. Stewart, "Preliminary Description of tive Ground Test Accelerator Cryogenic Cooling System," Ciyogenic Processes and Equipment, C. F. Gottzmann, I.. C. Kun, K. D. Timmerhaus, and I. Wenzel, Eds., Book No. H00455, (The American Society of Mechanical Engineers, New York, 1989), pp 111-116. 


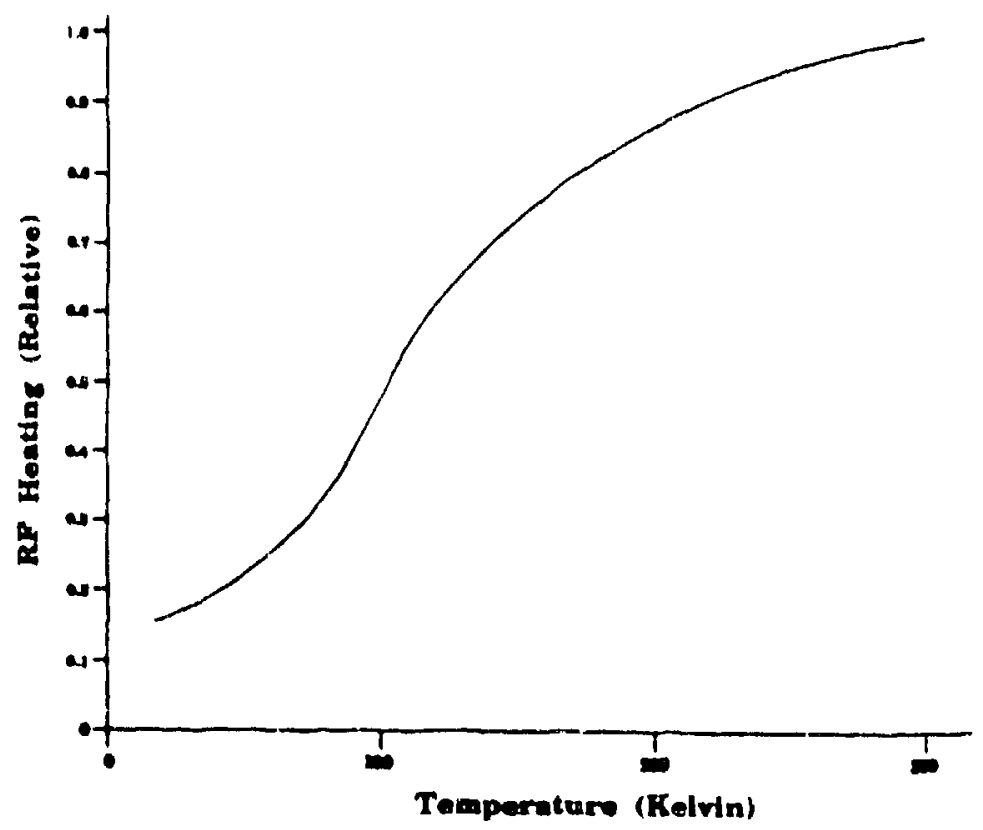

Fig. 1 Typical relationship of relative it-heating of copper as a function of temperature showing a dramatic reduction in if heating is obtained at low temperature. (This relationship is a function of RAR, surface treatment, and frequency.) 


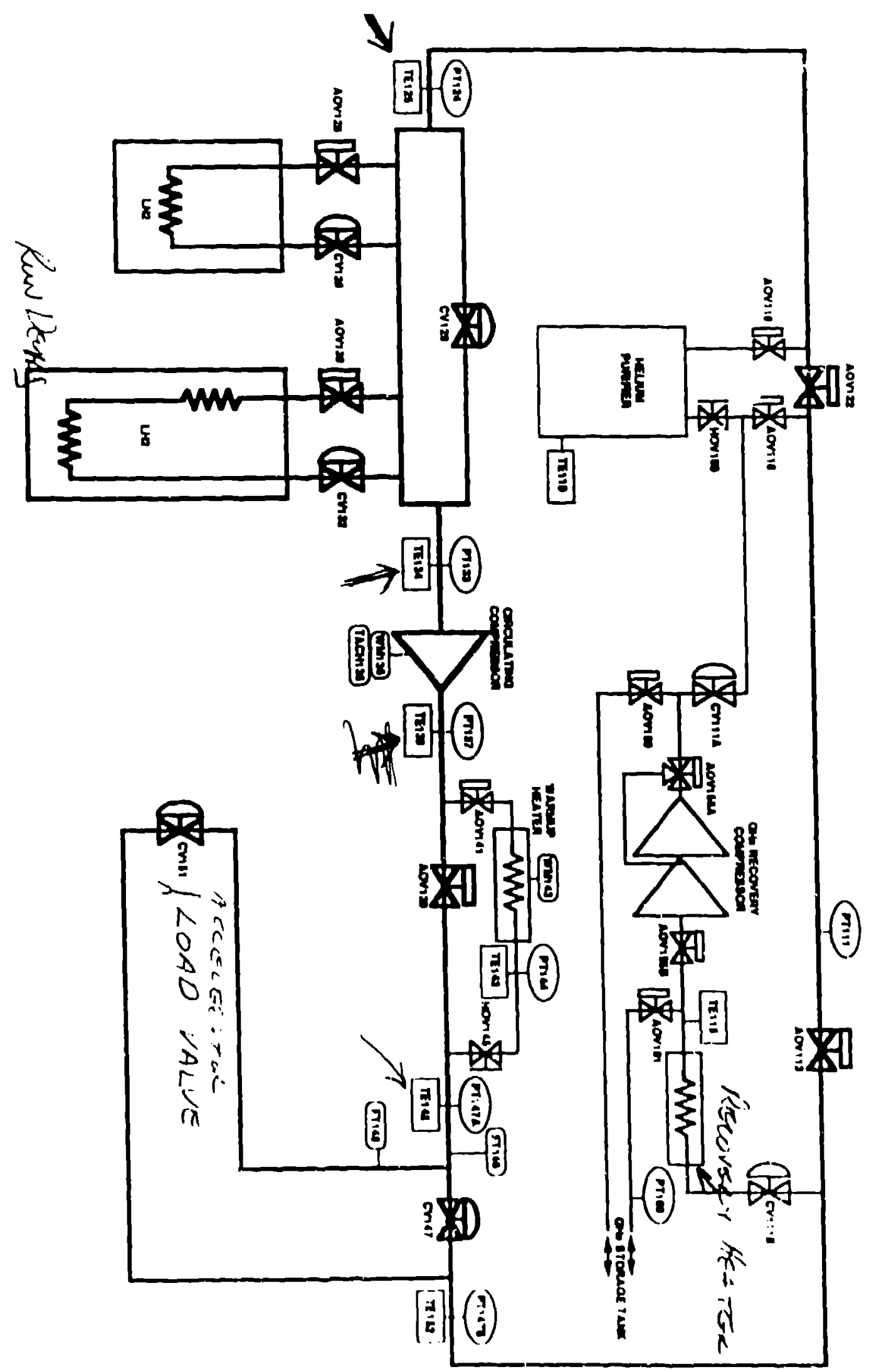

Fig. 2 Schematic of GiTA Cyroganic Cooling System 


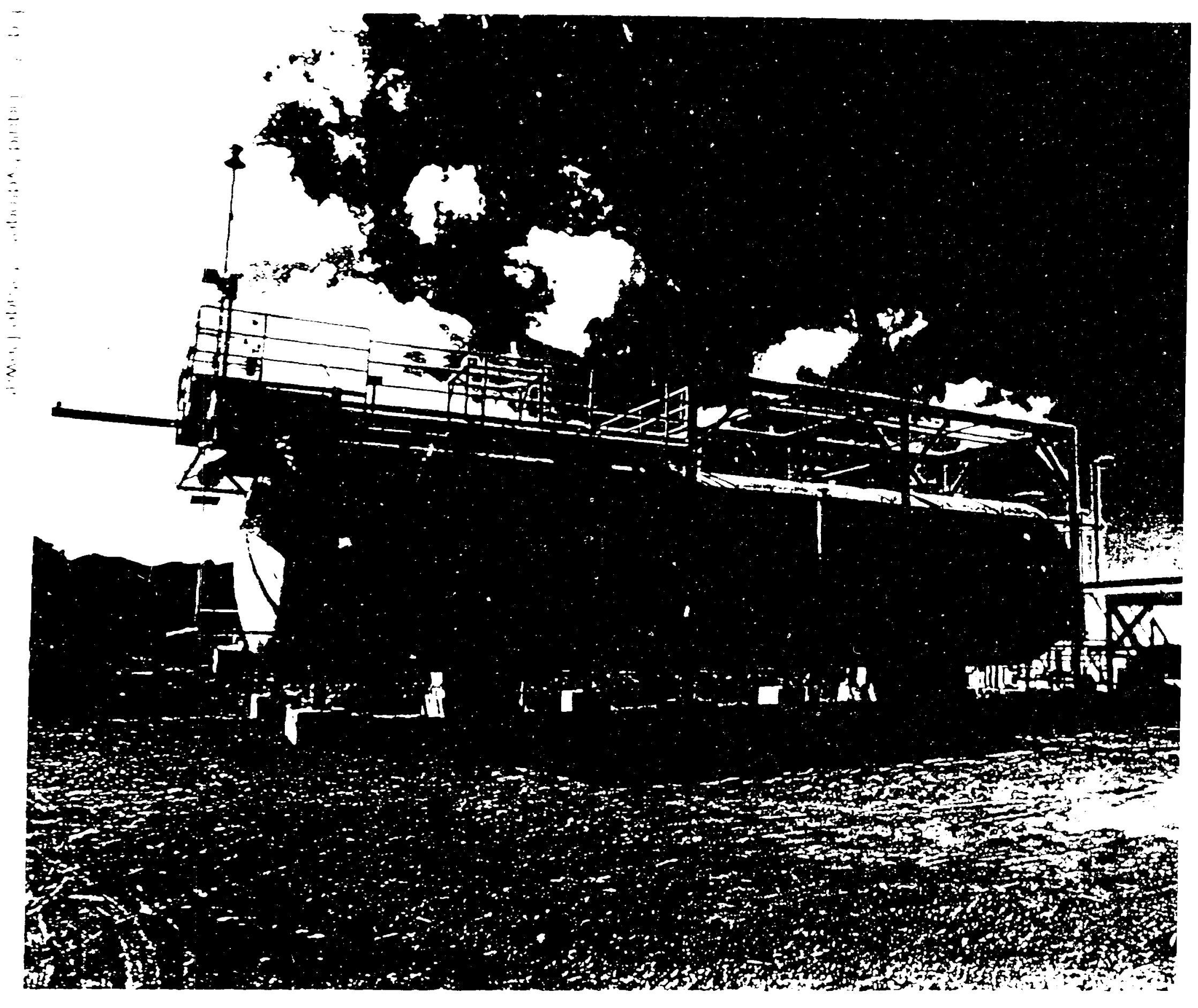




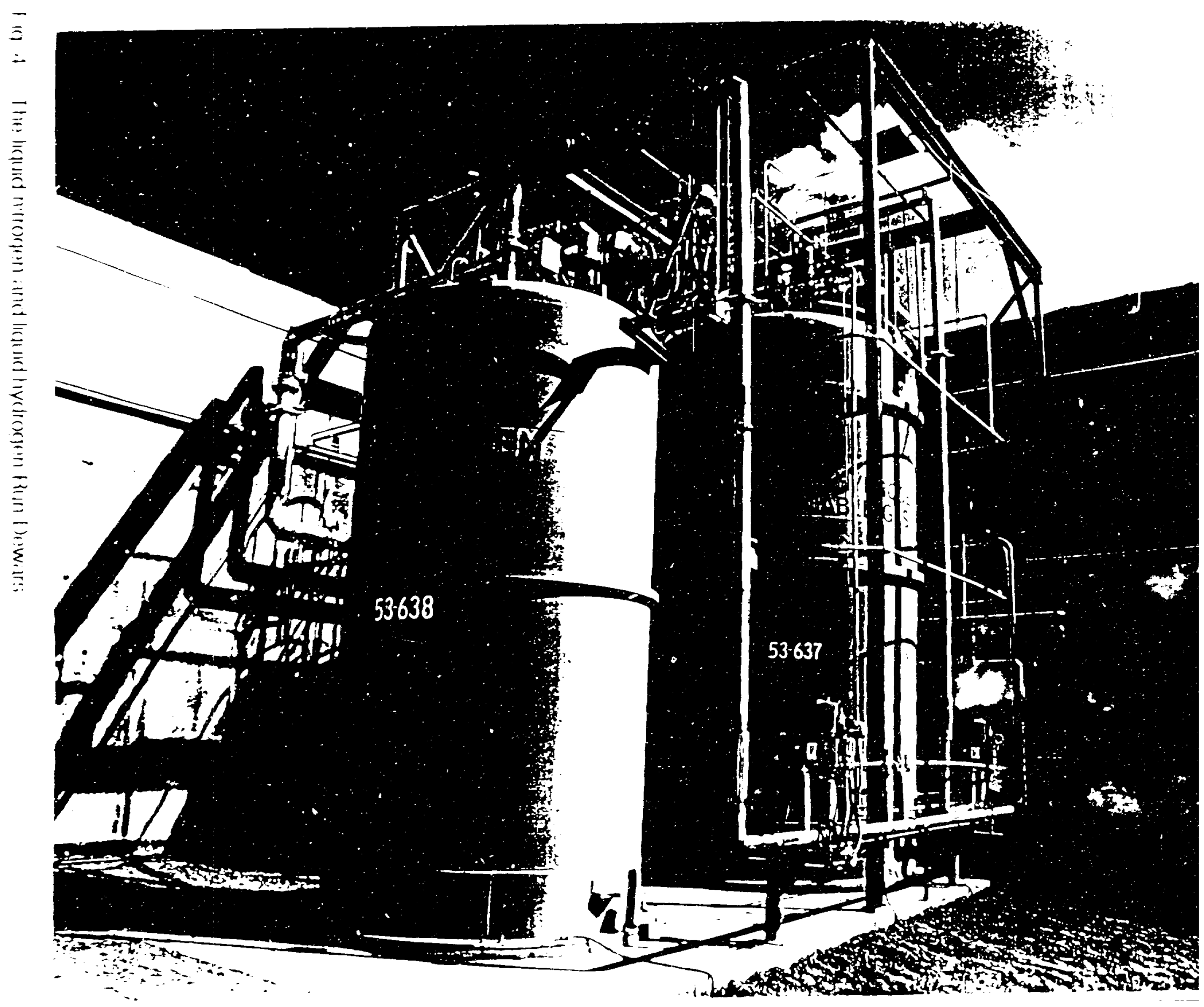




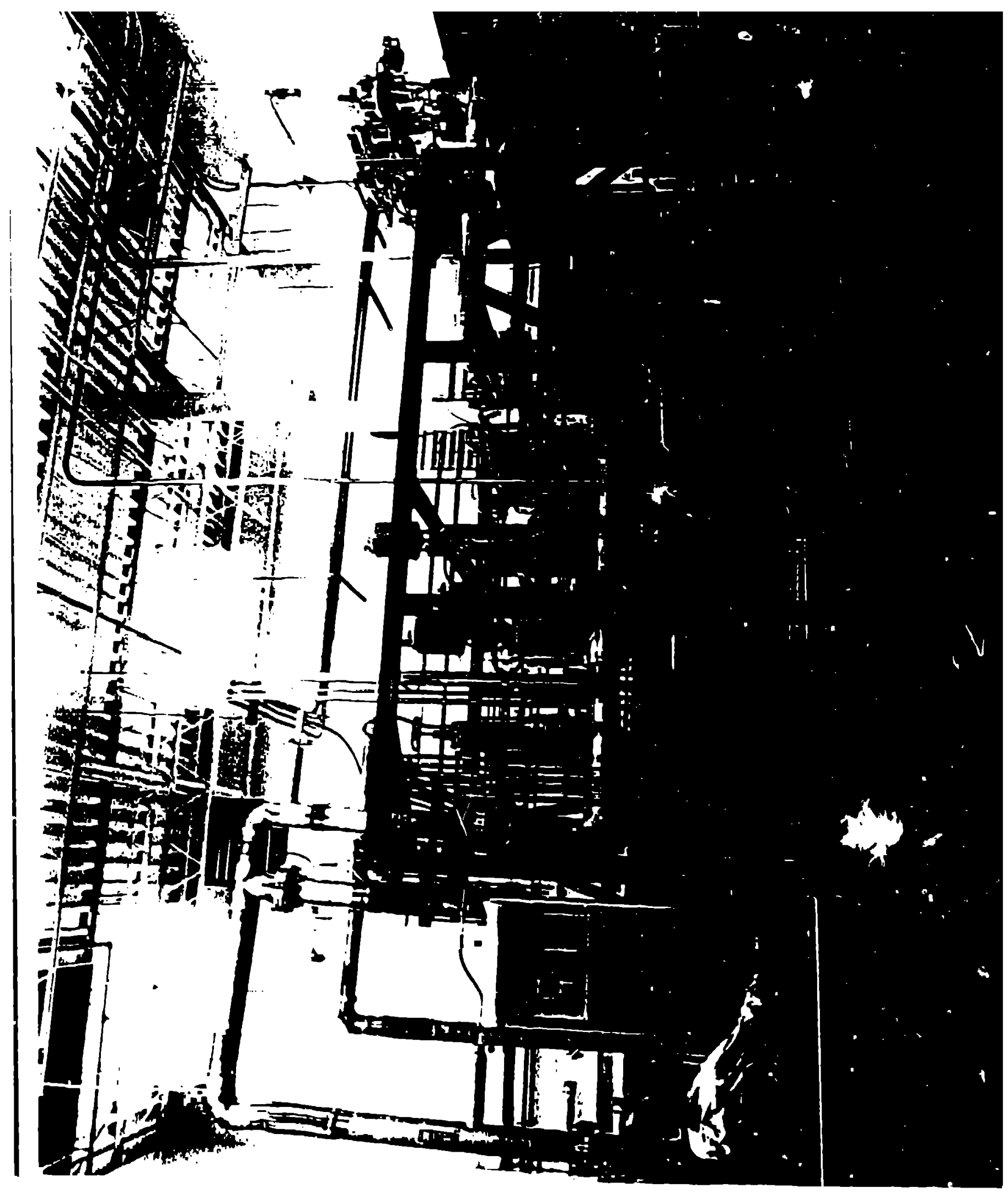

Fig. 5 The GTA equipment room containing the $\mathrm{He}$ circulation compressors, the purification system, heaters, bypass piping and valving, and local iristrumentation. 


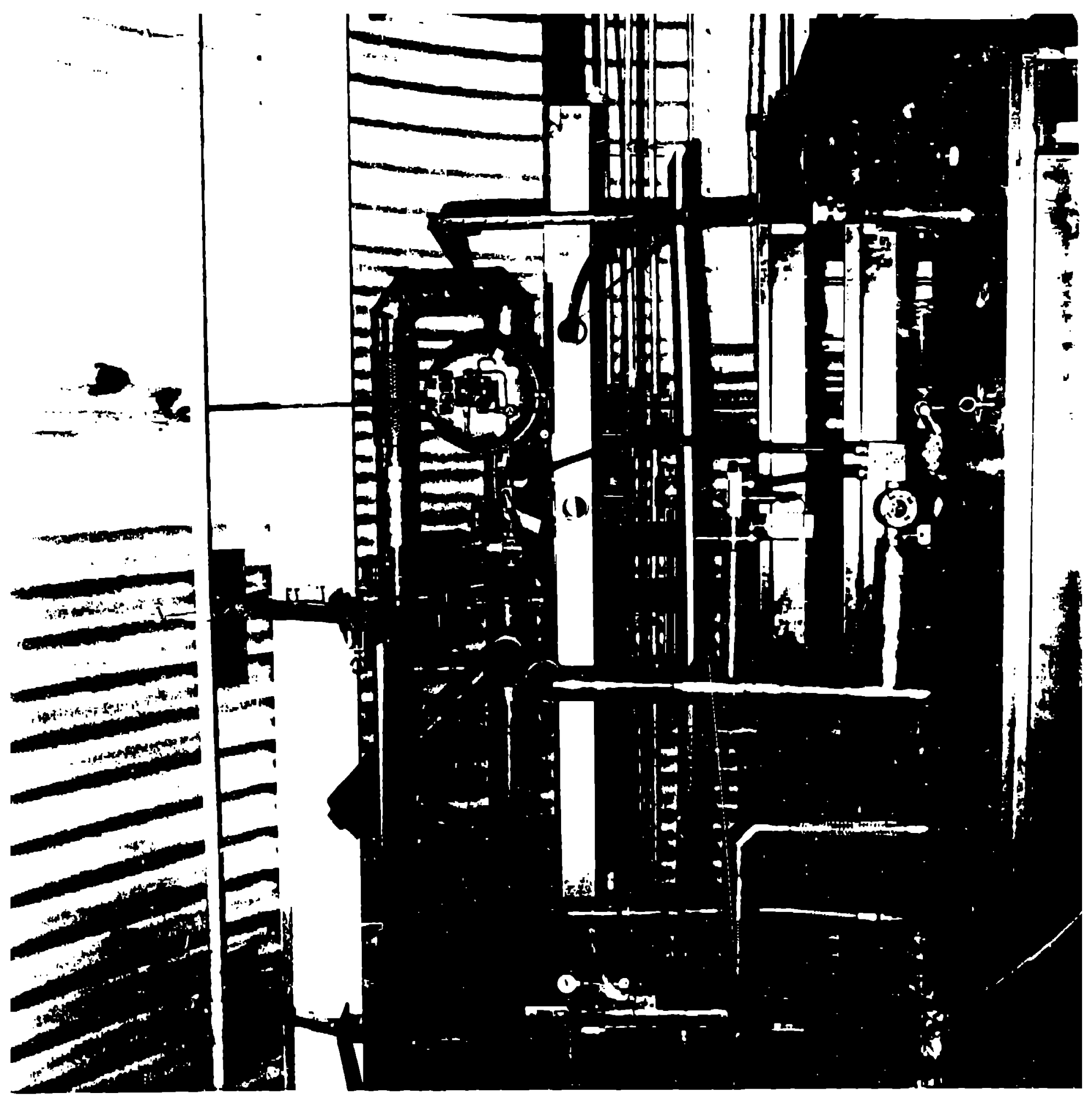

Fig. 6 GTA tunnel with the bypass valves CV 151 of the crycgenic cooling system. 


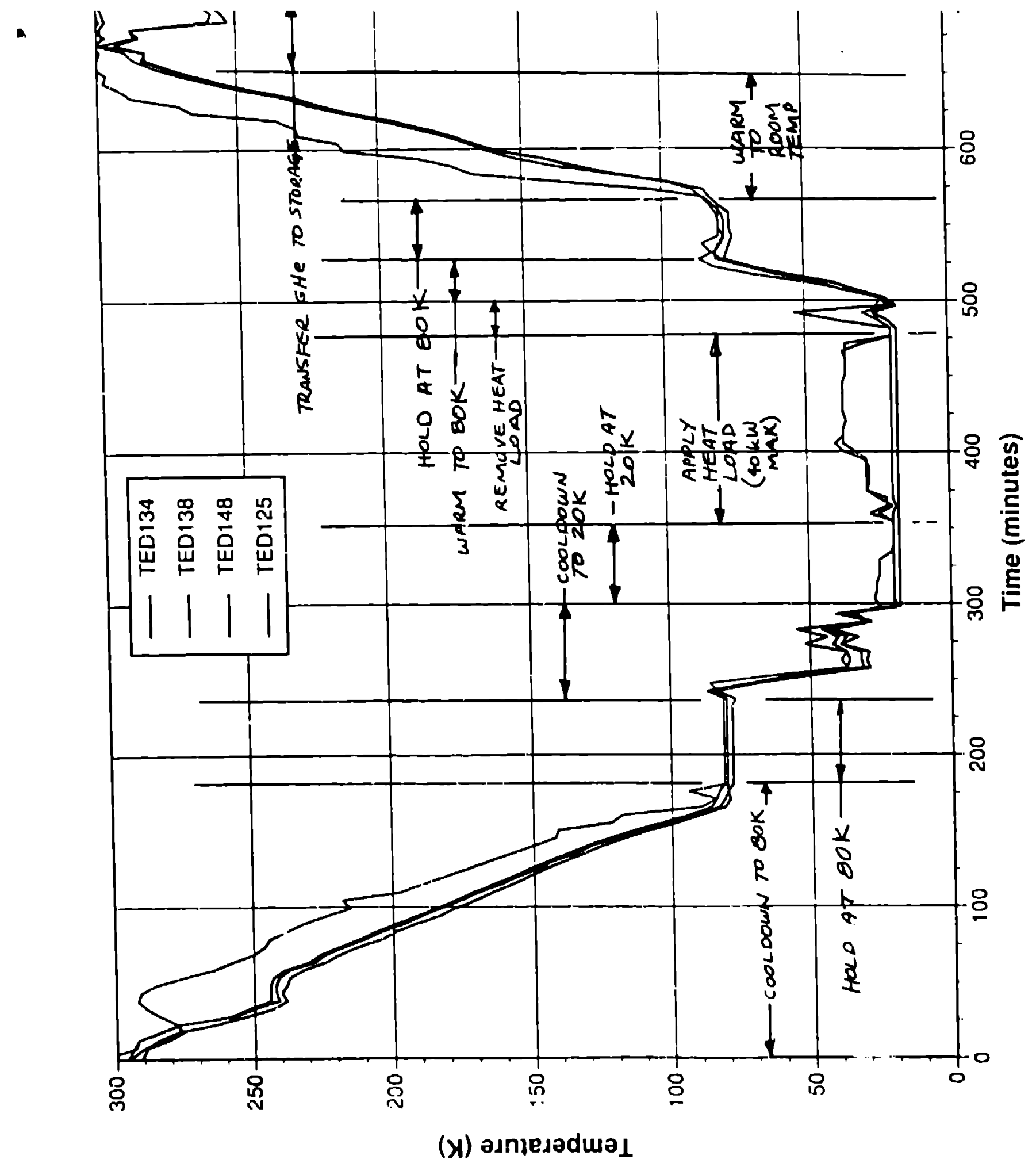

Fig. 7. Temperature history of the cryogenic cooling system checkout nun. 


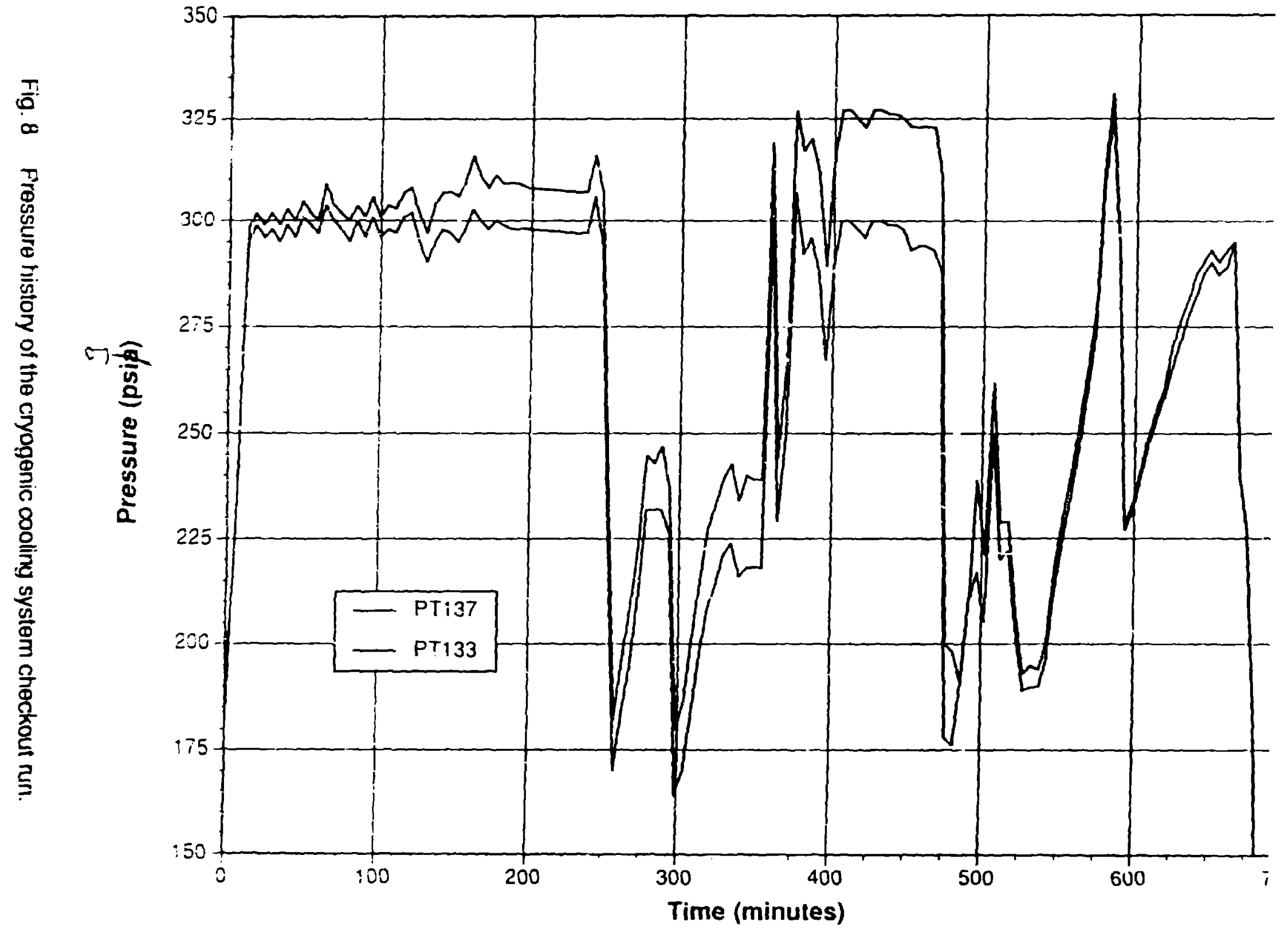

